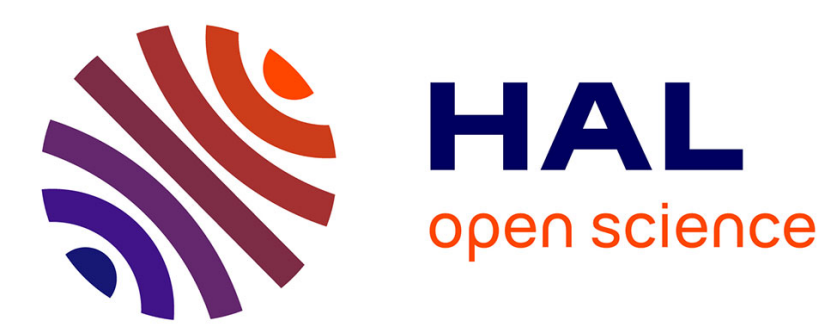

\title{
Carbon nanotube-functionalized silicon surfaces with efficient redox communication
}

Fanny Hauquier, Giorgia Pastorin, Philippe Hapiot, Maurizio Prato, Alberto Bianco, Bruno Fabre

\section{> To cite this version:}

Fanny Hauquier, Giorgia Pastorin, Philippe Hapiot, Maurizio Prato, Alberto Bianco, et al.. Carbon nanotube-functionalized silicon surfaces with efficient redox communication. Chemical Communications, 2006, 43, pp.4536-4538. 10.1039/B610559A . hal-00256530

\section{HAL Id: hal-00256530 \\ https://hal.science/hal-00256530}

Submitted on 23 Aug 2013

HAL is a multi-disciplinary open access archive for the deposit and dissemination of scientific research documents, whether they are published or not. The documents may come from teaching and research institutions in France or abroad, or from public or private research centers.
L'archive ouverte pluridisciplinaire HAL, est destinée au dépôt et à la diffusion de documents scientifiques de niveau recherche, publiés ou non, émanant des établissements d'enseignement et de recherche français ou étrangers, des laboratoires publics ou privés. 


\title{
Carbon nanotube-functionalized silicon surfaces with efficient redox communication $\dagger$
}

\author{
Fanny Hauquier, ${ }^{a}$ Giorgia Pastorin, ${ }^{b}$ Philippe Hapiot, ${ }^{a}$ Maurizio Prato, ${ }^{* c}$ Alberto Bianco ${ }^{* b}$ and \\ Bruno Fabre*a
}

Received (in Cambridge, UK) 24th July 2006, Accepted 29th August 2006

First published as an Advance Article on the web 18th September 2006

DOI: $10.1039 / \mathrm{b} 610559 \mathrm{a}$

Sidewall functionalized multi-walled carbon nanotubes can be covalently bound parallel to a silicon surface via a selfassembled acid-terminated monolayer used as an organic molecular glue.

Owing to their unique electrical, mechanical and thermal properties, the integration of carbon nanotubes (CNTs) with metallic or semiconducting substrates is a very promising approach for developing new nanoscale devices for future applications in electronics, optoelectronics and chemical/biological detection. ${ }^{1}$ However, the fabrication of CNT-based devices is severely hindered by the lack of simple and reliable methods to deposit this type of nanomaterial in a controlled fashion. Comparatively to the covalent attachment of CNTs to gold surfaces, ${ }^{2}$ the anchoring of CNTs to silicon substrates has been surprisingly much less developed. Several published procedures consisted in the controlled adsorption of CNTs on non-oxidized and oxidized silicon surfaces ${ }^{3}$ but the absence of a covalent link between the CNTs and the underlying substrate may render the architectures less stable and less robust. A nice example demonstrating the covalent attachment of CNTs to silicon has been recently reported by Tour and co-workers using orthogonally functionalized oligo(phenylene ethynylene) aryldiazonium salts as linker units. ${ }^{4}$

Herein, we propose an alternative and versatile method to build CNT-functionalized silicon surfaces with striking electrochemical characteristics which could be useful for electroanalytical applications. This approach is based on a surface amidation reaction between soluble amino sidewall functionalized multi-walled carbon nanotubes (MWNTs) ${ }^{5}$ and the $N$-hydroxysuccinimide headgroups of an alkyl monolayer covalently bound to $p$-type $\operatorname{Si}(111)$ (Fig. 1). This methodology offers several advantages. First, the molecular films produced from the reaction of hydrogen-terminated silicon surfaces $(\mathrm{Si}-\mathrm{H})$ with $\omega$-substituted 1-alkenes, used in this work, are usually well-ordered, densely packed and robust monolayers. ${ }^{6}$

${ }^{a}$ Matière Condensée et Systèmes Electroactifs, Sciences Chimiques de Rennes, UMR CNRS 6226, Université de Rennes 1, 35042, Rennes Cedex, France. E-mail: fabre@univ-rennes1.fr; Fax: +33 223 236732, Tel: +33223236550

${ }^{b}$ Institut de Biologie Moléculaire et Cellulaire, UPR CNRS 9021, Immunologie et Chimie Thérapeutiques, 67084, Strasbourg, France. E-mail: A.Bianco@ibmc.u-strasbg.fr; Fax: +33 388 610680;

Tel: +33388417088

${ }^{c}$ Dipartimento di Scienze Farmaceutiche, Università di Trieste, Piazzale Europa 1,34127.Trieste, Italy.E-mail:prato@units.it

$\dagger$ Electronic supplementary information (ESI) available: Experimental details for the synthesis of amino-substituted MWNTs, the preparation of the MWNT-modified $\mathrm{Si}(111)$ surfaces and fitting procedures of SECM data. See DOI: 10.1039/b610559a

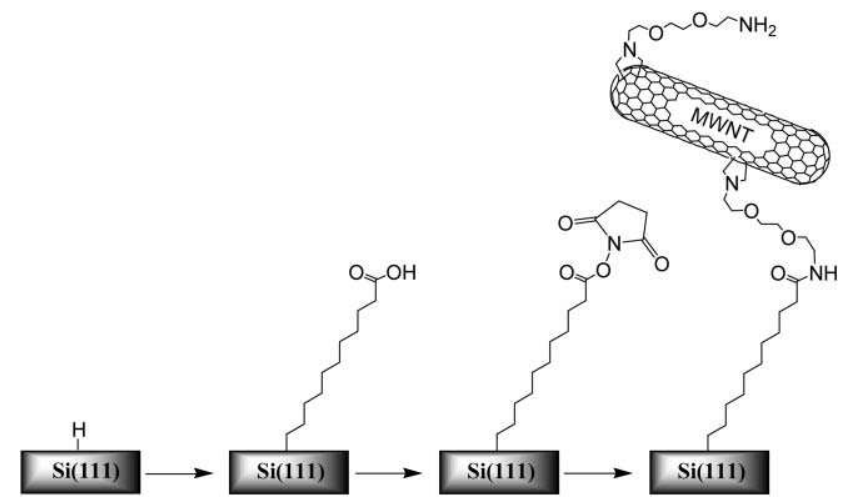

Fig. 1 Covalent assembly of MWNTs to $\mathrm{Si}(111)$ surfaces through a surface amidation reaction (see ESI for experimental details $\dagger$ ).

Second, activated esters react with amines under very mild conditions to form the corresponding amides in high yields. Thus, this surface chemistry is perfectly compatible with different nanolithography patterning technologies. Also interestingly, the surface coverage of CNTs can in principle be controlled by either diluting the acid-terminated chains with chemically inert $n$-alkyl chains of the starting monolayer or changing the amount of amino groups attached to MWNTs. Consequently, the excess of amino groups remained available on the MWNTs after the silicon binding can be further functionalized with other specific groups (e.g. enzymes or other biologically relevant molecules).

The immobilization of MWNTs was verified using scanning electron microscopy (SEM) (Fig. 2). The SEM images show the

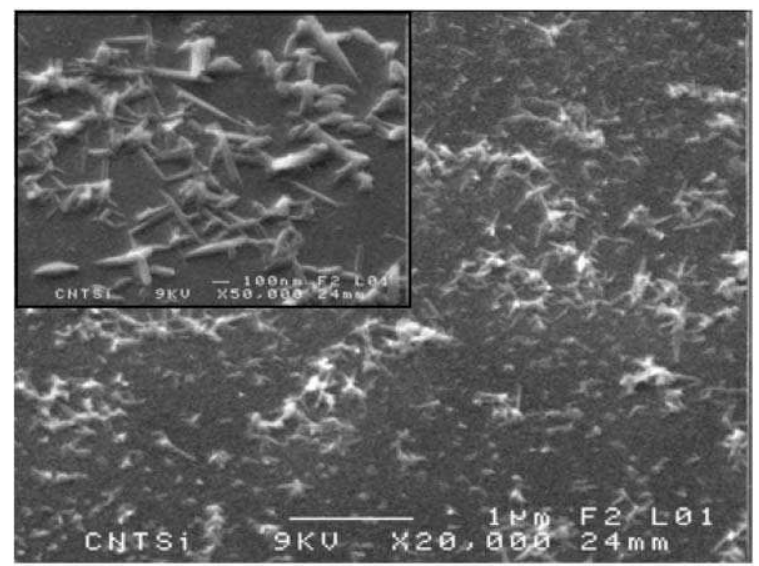

Fig. 2 SEM images of MWNTs bound to Si(111) surfaces. 
silicon surface highly covered by MWNTs with the tubes lying flat on the surface rather than perpendicular, consistent with the sidewall functionalization of the MWNTs by the amino groups. Such an assertion was also supported by atomic force microscopy (AFM) results. The SEM analysis of different representative areas enabled the surface coverage of MWNTs to be roughly estimated at $10^{9}-2 \times 10^{9}$ tubes $\mathrm{cm}^{-2}$. The attached MWNTs were observed predominantly as individual nanotubes of $20-60 \mathrm{~nm}$ in diameter. It must be pointed out that no MWNT deposition was observed using a silicon surface derivatized with the simple nonfunctionalized $n$-decyl monolayer. Moreover, as a result of the covalent link, the MWNTs were strongly adherent to the electrode surface as they were not removed by sonication (e.g. $10 \mathrm{~min}$ in $\mathrm{CH}_{2} \mathrm{Cl}_{2}$ ).

The electrochemical properties of the MWNT assemblies have been characterized by scanning electrochemical microscopy (SECM). ${ }^{7}$ SECM is based on the electrochemical interactions of a redox species produced at a probe ultramicroelectrode (UME) tip and the substrate under investigation. In the simplest mode used here (feedback mode), the substrate electrode is not electrically connected. After diffusion of the electrogenerated species to the sample, an electrochemical reaction is possible on a localized spot on the surface where the initial form of the mediator can be regenerated resulting in an enhancement of the current at the probe electrode.

A typical approach curve ${ }^{8}$ obtained at the MWNT-modified surface is shown in Fig. 3A using ferrocene as the reduced form of the redox mediator. For comparison, the curves obtained at $\mathrm{Si}(111)-\mathrm{H}$ and undecanoic acid monolayer-modified $\mathrm{Si}(111)$ are also shown. It must be noticed that the formal potential of the ferrocene/ferrocenium couple $E^{\circ \prime}=0.45 \mathrm{~V} v s$. SCE is more positive than the flat-band potential $E_{\mathrm{fb}}$ of the MWNT- and alkyl-modified electrodes (namely $0.00 \pm 0.02 \mathrm{~V}$ ) derived from capacitance measurements using the Mott-Schottky relation. Under these
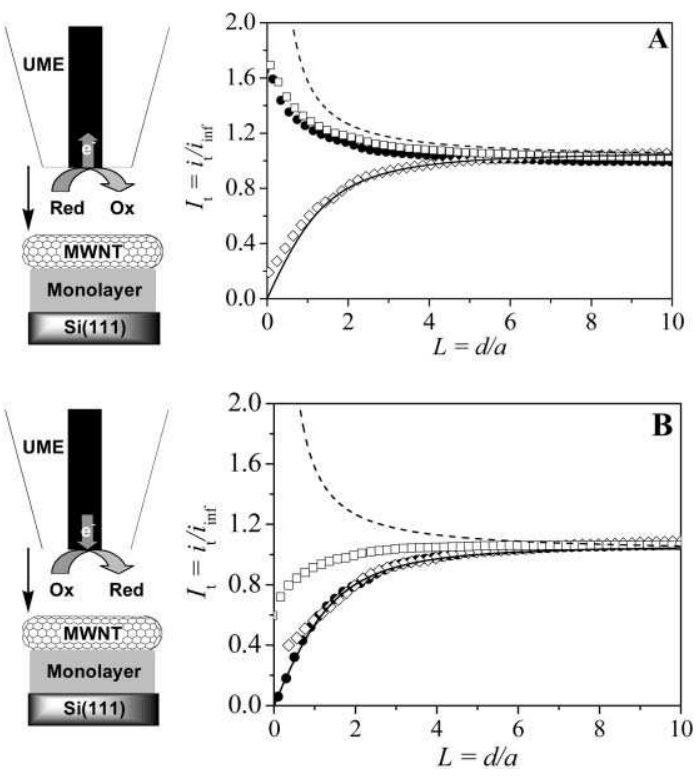

Fig. 3 SECM approach curves in the dark obtained at the ( $\square$ ) MWNT-, $(\diamond)$ undecanoic acid monolayer-modified $\mathrm{Si}(111)$ and $(\bullet) \mathrm{Si}(111)-\mathrm{H}$ in $\mathrm{DMF}+0.1 \mathrm{M} \mathrm{Bu} 4 \mathrm{NClO}_{4}$ containing $10^{-2} \mathrm{M}$ (A) ferrocene or (B) azobenzene as mediator. The solid and dashed lines are theoretical curves for totally insulating and conducting substrates respectively. $a=10 \mu \mathrm{m}$. conditions, the $p$-type silicon surface in contact with the electrolytic solution can be considered in carrier accumulation ${ }^{9}$ and thus behaves as a quasi-metallic electrode. ${ }^{10}$

For $L>5, I_{\mathrm{t}}$ is close to one for all the curves as no interaction occurs between the electrogenerated ferrocenium species and the substrate for this distance range. For $L<5, I_{\mathrm{t}}$ is found to rapidly diminish for the undecanoic acid monolayer. This negative feedback confirms the blocking properties of this monolayer which limits the regeneration of the mediator (the measured apparent charge-transfer rate constant $k_{\text {app }}$ is $8 \times 10^{-5} \mathrm{~cm} \mathrm{~s}^{-1}$ ). In the case of the MWNT-modified surface, $I_{\mathrm{t}}$ enhances dramatically for the lowest values of $L$. This positive feedback is caused by the reduction of the ferrocenium at the modified electrode with a rate as high as that determined at a $p$-type $\mathrm{Si}(111)-\mathrm{H}$ electrode, i.e. $k_{\text {app }}=1.5 \times 10^{-2} \mathrm{~cm} \mathrm{~s}^{-1}$ (see ESI, Fig. S2 $\dagger$ ).

In order to independently evaluate the redox contribution of the attached MWNTs, SECM measurements have also been performed with the cathodic mediator azobenzene. Indeed, the cathodic reduction of azobenzene to its radical anion occurring at a potential much lower than $E_{\mathrm{fb}}\left(E^{\circ}=-1.3 \mathrm{~V} v s\right.$. SCE $)$, the regeneration of this mediator does not take place on $p$-type silicon without illumination, in agreement with previous voltammetric studies. ${ }^{11}$ As expected, the approach curves monitored for the undecanoic acid monolayer and $\mathrm{Si}(111)-\mathrm{H}$ fit the theoretical curve for an insulating substrate (Fig. 3B). In contrast, the oxidized form of the mediator can be regenerated at the MWNT-modified surface with a rate constant $k_{\text {app }}$ of $1.7 \times 10^{-3} \mathrm{~cm} \mathrm{~s}^{-1}$ (see ESI, Fig. S3 $\uparrow$ ). In that case, the electrode behaves as an inert surface partially covered by randomly distributed redox-active nanotubes. So, it is expected that the effective rate constant is directly related to the fraction of active surface. ${ }^{12}$ Indeed, we observe that the regeneration rate is dependent on the MWNT surface coverage ${ }^{13}$ thus demonstrating that the regeneration of the mediator from the only network of attached MWNTs can occur with a high rate.

From SECM results, three major pathways can be considered to regenerate the initial form of the mediator: $(a)$ direct hole tunneling through the monolayer linker, $(b)$ diffusion of the electroactive species through the pinholes of the monolayer followed by the injection of a hole into the valence band of silicon and (c) charge transfer at the attached conducting MWNTs (Scheme 1).
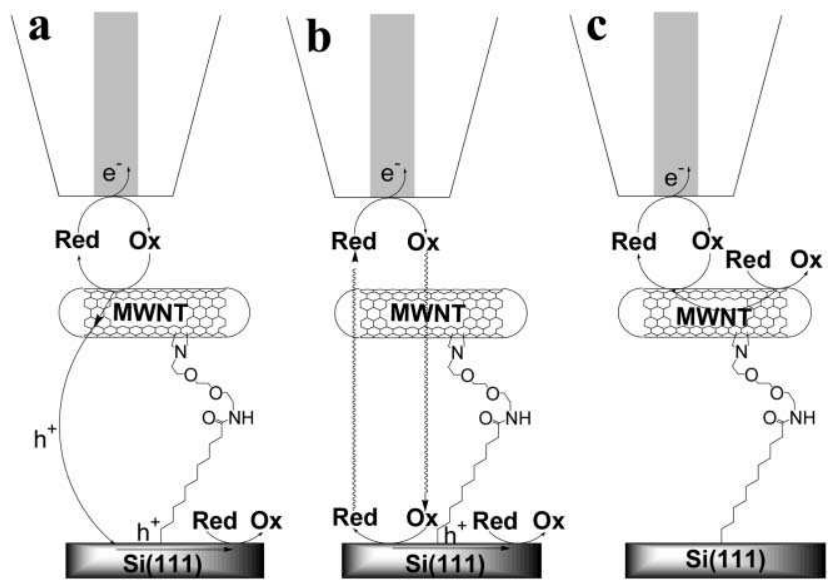

Scheme 1 SECM in feedback mode for studying charge-transfer kinetics at a non-connected MWNT-modified $p$-type $\mathrm{Si}(111)$ surface. 


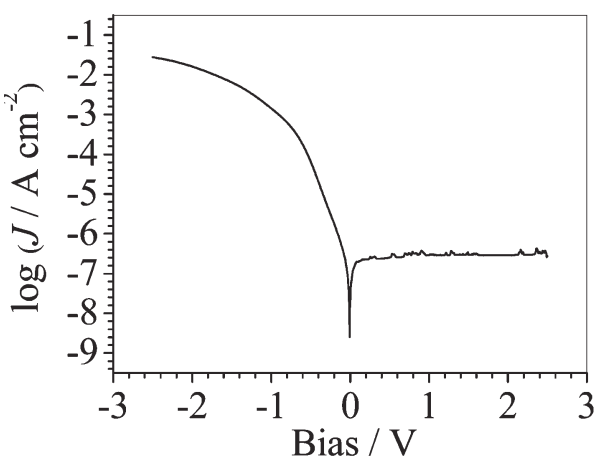

Fig. $4 J-V$ characteristics of the $(+) H g / M W N T / m o n o l a y e r / p-\operatorname{Si}(111)(-)$ junction. The rectification ratio is $c a .5 \times 10^{4}$ at $\pm 2 \mathrm{~V}$.

Although the occurrence of a charge transfer through the pinhole defects of the monolayer bridge cannot be ruled out, its contribution in the overall charge-transfer process is expected to be small because both long-chain alkyl ${ }^{14}$ and undecanoic acid monolayers showed good blocking properties in the presence of the ferrocene mediator. Moreover, the possibility of a direct electrical connection between MWNT and the silicon surface so creating a "short-circuit" seems unlikely as a major pathway in the mechanism of charge transport. To test the occurrence of such a "short-circuit", a mercury contact was formed to the MWNTmodified silicon surface. A typical current density-applied bias voltage $(J-V)$ curve of the $\mathrm{Hg} / \mathrm{MWNT} /$ monolayer/silicon junction is shown in Fig. 4. A Schottky diode rectifying behaviour is clearly observed with a transport mechanism governed by a thermionic emission process as is generally the case for metal/insulator/ semiconductor (MIS) diodes. ${ }^{15}$ Furthermore, the shape and the magnitude of the $J-V$ curve are found to be similar to those obtained for other alkyl monolayer-based silicon devices. ${ }^{16}$

In conclusion, the functionalized MWNT assemblies prepared in this study allow an efficient electrical communication between the semiconductor surface and a redox probe in solution. Further SECM investigations with a polarized electrode configuration are currently in progress in order to elucidate the mechanism involved in the redox communication. We believe that such modified surfaces can be useful for electrically transducing an biomolecular recognition event

This work has been supported by CNRS, University of Trieste and MIUR (PRIN 2004, prot. 2004035502). F. H. and G. P. are recipients of a fellowship from MNRT. Dr. J. Ghilane (Université de Rennes 1) is fully acknowledged for his help in SECM experiments.

\section{Notes and references}

* Firstly, $p$-type $\mathrm{Si}(111)-\mathrm{H}$, prepared by etching a clean silicon shard in ppb grade $\mathrm{NH}_{4} \mathrm{~F} 40 \%$ for $15 \mathrm{~min}$, was reacted photochemically at $300 \mathrm{~nm}$ for
$3.5 \mathrm{~h}$ with undecylenic acid to provide a $\mathrm{COOH}$-terminated alkyl monolayer. Then, the terminal $\mathrm{COOH}$ groups were activated with NHS by immersing the modified silicon surface for $3 \mathrm{~h}$ in a freshly prepared mixture of a deaerated DMF solution containing EDC at $0.2 \mathrm{M}$ and NHS at $0.1 \mathrm{M}$. The covalent attachment of MWNTs on Si(111) was performed by immersing overnight the NHS-activated silicon surface in a DMF solution containing $c a .1 \mathrm{mg} \mathrm{mL}-1$ of ammonium-substituted MWNTs previously neutralized with diisopropylethylamine (amount of amino groups: $0.50 \mathrm{mmol}$ per $\mathrm{g}$ of MWNTs).

1 M. S. Dresselhaus, G. Dresselhaus and P. C. Eklund, Science of fullerenes and carbon nanotubes, Academic Press, New York, 1996; R. Saito, M. S. Dresselhaus and G. Dresselhaus, Physical properties of carbon nanotubes, Imperial College Press, London, 1998; P. M. Ajayan, Chem. Rev., 1999, 99, 1787.

2 L. Sheeney-Haj-Ichia, B. Basnar and I. Willner, Angew. Chem., Int. Ed., 2005, 44, 78; J. J. Gooding, R. Wibowo, J. Liu, W. Yang, D. Losic, S. Orbons, F. J. Mearns, J. G. Shapter and D. B. Hibbert, J. Am. Chem. Soc., 2003, 125, 9006; P. Diao and Z. Liu, J. Phys. Chem. B, 2005, 109, 20906.

3 K. H. Choi, J. P. Bourgoin, S. Auvray, D. Esteve, G. S. Duesberg, S. Roth and M. Burghard, Surf. Sci., 2000, 462, 195; T. Hertel, R. Martel and P. Avouris, J. Phys. Chem. B, 1998, 102, 910; M. Burghard, G. Duesberg, G. Philipp, J. Muster and S. Roth, Adv. Mater., 1998, 10, 584; J. Liu, M. J. Casavant, M. Cox, D. A. Walters, P. Boul, W. Lu, A. J. Rimberg, K. A. Smith, D. T. Colbert and R. E. Smalley, Chem. Phys. Lett., 1999, 303, 125; J. Im, J. Kang, M. Lee, B. Kim and S. Hong, J. Phys. Chem. B, 2006, 110, 12839.

4 A. K. Flatt, B. Chen and J. M. Tour, J. Am. Chem. Soc., 2005, 127, 8918; J. He, B. Chen, A. K. Flatt, J. J. Stephenson, C. D. Coyle and J. M. Tour, Nat. Mater., 2006, 5, 63.

5 D. Tasis, N. Tagmatarchis, A. Bianco and M. Prato, Chem. Rev., 2006, 106, 1105; A. Bianco and M. Prato, Adv. Mater., 2003, 15, 1765.

6 J. M. Buriak, Chem. Rev., 2002, 102, 1271; D. D. M. Wayner and R. A. Wolkow, J. Chem. Soc., Perkin Trans. 2, 2002, 23.

7 A. J. Bard and M. V. Mirkin, Scanning electrochemical microscopy, Marcel Dekker, New York, 2001; A. J. Bard, F.-R. F. Fan, D. T. Pierce, P. R. Unwin, D. O. Wipf and F. Zhou, Science, 1991, 254, 68

8 Plot of the normalized current $I_{\mathrm{t}}=i_{\mathrm{t}} / i_{\text {inf }} v$ s. the normalized distance $L=d l a$ where $i_{\mathrm{t}}$ is the current at the tip electrode localized at a distance $d$ from the substrate, $i_{\text {inf }}$ is the steady-state current when the tip is at an infinite distance from the substrate and $a$ is the radius of the UME.

9 X. G. Zhang, Electrochemistry of silicon and its oxide, Kluwer Academic, New York, 2001.

10 The cyclic voltammogram of ferrocene at a $p$-type $\mathrm{Si}(111)-\mathrm{H}$ electrode gives a fully reversible system. B. Fabre and F. Hauquier, J. Phys. Chem. $B, 2006,110,6848$.

11 A. B. Bocarsly, D. C. Bookbinder, R. N. Dominey, N. S. Lewis and M. S. Wrighton, J. Am. Chem. Soc., 1980, 102, 3683.

12 C. Amatore, J. M. Savéant and D. Tessier, J. Electroanal. Chem., 1983, 146, 37.

13 F. Hauquier, G. Pastorin, P. Hapiot, M. Prato, A. Bianco and B. Fabre, unpublished work.

14 J. Ghilane, F. Hauquier, B. Fabre and P. Hapiot, Anal. Chem., 2006, 78 , 6019.

15 S. M. Sze, Semiconductor Devices: Physics and Technology, Wiley, New York, 1985.

16 Y.-J. Liu and H.-Z. Yu, J. Phys. Chem. B, 2003, 107, 7803; E. J. Faber, L. C. P. M. de Smet, W. Olthuis, H. Zuilhof, E. J. R. Sudhölter, P. Bergveld and A. van den Berg, ChemPhysChem, 2005, 6, 2153. 